\title{
Effects of heat waves on human mortality, Galicia, Spain
}

\author{
M. deCastro ${ }^{1, *}$, M. Gomez-Gesteira ${ }^{1}$, A. M. $\operatorname{Ramos}^{1}$, I. Álvarez ${ }^{1,2}$, P. deCastro ${ }^{3}$ \\ ${ }^{1}$ EPphysLab (Environmental Physics Laboratory), Universidade de Vigo, 32004 Ourense, Spain \\ ${ }^{2}$ CESAM, Universidade de Aveiro, Departamento de Física, 3810-193 Aveiro, Portugal \\ ${ }^{3}$ Complejo Hospitalario Universitario de Vigo (CHUVI), Servizo Galego de Saúde (SERGAS), 36204 Vigo, Spain
}

\begin{abstract}
Two major heat waves were identified in Galicia over the period 1987-2006. The first was detected in July 1990, and the second in August 2003. The most likely factor contributing to both heat waves was the north-eastward displacement of the Atlantic subtropical high. The effect of these heat waves on excessive mortality was assessed through the analysis of temperature means and normalized mortality exceedance of the 95th percentile of maximum temperature and mortality. The study was disaggregated by province, gender and age, but only the population segment older than $65 \mathrm{yr}$ was targeted. In terms of temperature exceedance, the 2003 heat wave was slightly more intense than the one in 1990. However, the resulting mortalities were much higher in 1990; this difference is possibly due to improvements in welfare that occurred in the interim period. For both heat waves, effects were more severe in women than in men.
\end{abstract}

KEY WORDS: Heat waves · Mortality · Galicia

\section{INTRODUCTION}

Heat waves (HWs) are considered to be the major cause of weather-related deaths. A basic definition of a HW is an extended period of unusually high temperatures which causes wildlife ativity and changes in human behaviour and can cause severe health problems (Robinson 2001). Studies carried out by the U.S. National Weather Service indicated that HWs cannot be considered a rare phenomenon. In fact, during the last decades there has been a considerable increase in public attention on extreme temperature events and their health and environmental effects. The summers of 1980 in St. Louis and of 1995 in Chicago were affected by 'killing HWs'. Europe has also suffered intense HWs in recent years such as the episodes that occurred in France in 1976, Portugal in 1981 and 1991, Greece in 1987, the UK in 1995 and most of western central Europe in 2003 (IVS 2003). Thus, the number of studies dealing with mortality associated with intense HWs has increased during recent years (e.g. Dessai 2002, Davis et al. 2003, Díaz et al. 2006, Trigo et al. 2009). Trigo et al. 2009 observed that the excess deaths in Portugal associated with the 1981 and 1991 HWs were smaller than those attributed to the 2003 event.
Monthly temperatures measured for June and August 2003 in central Europe were beyond the historical range (Schär et al. 2004), and summer 2003 was considered to be the warmest in Europe since the 16th century (Luterbacher et al. 2004). According to Díaz et al. (2006), during the first 2 wk of August 2003 several countries measured new all time records of daily maximum temperature: $38.1^{\circ} \mathrm{C}$ in Great Britain, $40.2^{\circ} \mathrm{C}$ in Germany, $41.5^{\circ} \mathrm{C}$ in Switzerland and $47.5^{\circ} \mathrm{C}$ in Portugal. The Spanish absolute record was not broken $\left(50^{\circ} \mathrm{C}\right.$ in Sevilla in 1881), but according to the Spanish Agency of Meteorology (AEMET, www.aemet.es), several weather stations recorded daily maximum temperatures $\geq 40^{\circ} \mathrm{C}$ with unprecedented frequency.

The economic losses due to an increased strain on infrastructure and services, crop shortfall, wildfire activity or increased mortality highlight the effects of HWs on the environment and society. According to García-Herrera et al. (2010), 40000 extra deaths, particularly those of elderly Europeans, were directly attributable to the $2003 \mathrm{HW}$, with total economic losses exceeding US $\$ 10$ billion (Munich Re 2004).

According to the Intergovernmental Panel on Climate Change (IPCC 2007), in the 21st century the Medi- 
terranean basin-which includes southern Europe, northern Africa and Middle East-will be one of the prominent climate 'hot spots' in the world. The Mediterranean basin will be drier and it will experience a large number of extremely hot events with an increase of intense precipitations and an increase in summer HW frequency and duration (Della-Marta et al. 2007, Diffenbaugh et al. 2007). Kuglitsch et al. 2010 found that since the 1960s, the mean HW intensity, length and number increased by a factor of $7.6 \pm 1.3$, $7.5 \pm 1.3$ and $6.2 \pm 1.1$, respectively, in the eastern Mediterranean basin. This suggest that the occurrence of HWs in this region is higher than previously reported. A study carried out in 2 large Iberian cities, Madrid and Lisbon (García-Herrera et al. 2005), showed that in both cities there is a triggering effect on mortality when maximum daily temperature exceeds a given threshold $\left(34^{\circ} \mathrm{C}\right.$ in Lisbon and $36^{\circ} \mathrm{C}$ in Madrid). The effect is similar in both cases with significant mortality values occurring up to $3 \mathrm{~d}$ after the temperature threshold has been surpassed. Lisbon shows a higher mortality rate $(31 \%)$ than Madrid $(21 \%)$, which can be attributed to demographic and socio-economic factors. In addition, in both cities women are more susceptible than men to heat effects with the increase in mortality for women being twice that for man. Similar studies carried out by Trigo et al. (2009) in 18 districts of Portugal for the $2003 \mathrm{HW}$, showed a $58 \%$ increase, over expected deaths, with a markedly higher increase for women than for men (79 vs. $41 \%$, respectively). This gender difference is especially clear for ages above 75 yr, with an increase of 58 and $99 \%$ in male and female mortality, respectively. Previous studies show that people over $65 \mathrm{yr}$ are the most sensitive to extreme HWs, because thermal susceptibility increases with advancing age. Reduced thermoregulatory responses and less sensitive thermal perception may aggravate cardiovascular disease risk factors and trigger events like thrombosis or cardio vascular accidents (Pan et al. 1995).

García-Herrera et al. (2005) and Trigo et al. (2009) analyzed the effect of extreme summer temperatures on mortality by means of the temperature exceedance of a fixed percentile of all observed maximum temperature, and of the number of days with daily maximum temperature above the threshold, taking into account the intensity, duration and local character of the HW. Mortality rises dramatically when daily maximum temperature exceeds the 95th percentile of the local maximum temperature $\left(\mathrm{T}_{\max }\right.$ ) (Díaz et al. 2006, Gershunov et al. 2009) which is attributable to a failure of adaptive physiological mechanisms (Havenith 2001).

Some authors (Dessai 2002, Díaz et al. 2004, Trigo et al. 2009) have considered that humidity is not really important when studying the effects of HWs in the
Iberian region, because levels tend to be very low there. Typical synoptic characteristics of Iberian HWs episodes are intense advection of hot and very dry air from north Africa and intense subsidence of air masses (García-Herrera et al. 2005). Thus, for this region, the use of humidity indices does not improve the model adjustment obtained from purely thermal indices.

There are 2 major aspects in a HW: 'physiological', related to the general thermoregulation of the human body, and 'sociological', related to local adaptations to climate (Robinson 2001). It is now accepted that there is an adaptation effect of human communities to local weather conditions. Prior conditioning, both through living in a particular climate and through recent exposure to extreme events, has an influence in cultural protection to outdoor extreme temperatures (Kalkstein 1993). Social and cultural practices also play a significant role in the human perception of and response to heat. These may involve having a 'siesta' or adopting housing and urban forms, which for example, maximize air movement day and night and provide adequate shade during the daylight. The use of air conditioning systems in hospitals can also markedly reduce mortality (INS 2008). Nevertheless, populations adapt slowly to possible changes in intensity, frequency and duration of HWs. Recently, the main features associated with the 2003 European HW have been analyzed by García-Herrera et al. (2010), and suggest that the 2003 HW was caused by an anomalously persistent northerly displacement of the Atlantic subtropical high with a temperature anomaly amplified by a severe soil moisture deficit generated as a consequence of below average precipitation in the previous winter and spring.

According to García-Herrera et al. (2010), age was the most important single factor associated with an excess mortality that is higher for women than for men partly because of the lower number of men in elderly population age groups and partly because older women suffer more often than men from problems of thermoregulation. They also found that the social status of HW fatalities was a relevant factor, with lower social class groups more at risk. Fortunately, from a European public health perspective, the 2003 HW has represented a real landmark. The observed excess in mortality marked a turning point in the design and implementation of European prevention plans which until then had been absent except for Lisbon and Rome that already had in place heat wave alert systems. At the present, most European cities possess extreme temperature prevention and alert plans.

Galicia (NW of the Iberian Peninsula) was a region characterized by an aged population $(\sim 13 \%$ was older than $65 \mathrm{yr}$ in the 1980s and $22 \%$ in 2007) that is more sensitive to extreme HWs. However, the effect of temperature on mortality has received little attention in 
this area. As far as we know the only research article dealing with health and environmental factors was written by Lage et al. (1999). Their study aimed to establish the possible association between the number of emergency room admissions at the Juan Canalejo Hospital in Coruña due to organic, circulatory and respiratory reasons and the weather variables.

The identification of HWs in Galicia and their impact on excessive mortality from 1987 to 2006, has only been possible since the 1980s with the development of a reliable archive of mortality data. The impact on excessive mortality will be computed for those days when the maximum temperature exceeds the 95th percentile of the of the local $\mathrm{T}_{\max }$.

\section{DATA AND ANALYSIS}

\subsection{Data}

Mortality data sorted by province, day, gender and age were provided by the Servicio de Epidemioloxía, SERGAS (www.sergas.es). In previous studies (Trigo et al. 2009) the mortality exceeded was mostly attributed to the population segment over $65 \mathrm{yr}$, the most sensitive to extreme heat events, and thus this will be the only group targeted in the present study.

Gridded $\left(2.5^{\circ} \times 2.5^{\circ}\right)$ meteorological large-scale parameters were extracted from the National Center for Environmental Prediction/National Center for Atmospheric Research (NCEP/NCAR) reanalysis data obtained from the Climate Prediction Center (Kalnay et al. 1996; www.cdc.noaa.gov/cdc/reanalysis/reanalysis. shtml). In the present study, the $500 \mathrm{hPa}$ geopotential height, the $850 \mathrm{hPa}$ temperature and the sea-level pressure (SLP) fields will be considered. The air temperature field selected is sufficiently near the surface to be representative of the low troposphere state and it is not affected by topography. Daily data covering the North Atlantic area were selected for the present study.

The air temperature dataset measured at different land stations situated along Galicia was obtained from the AEMET. The location and altitude of these stations can be seen in Table 1. Daily maximum temperature data for the 1987-2006 period were considered in the present study. Data from this database underwent a quality control procedure with substitutions made for poor quality and some missing data, resulting in less than $1 \%$ of missing data and $90 \%$ of correlation with neighbor stations. This analysis is similar to the one used in the database of the National Climate Data Center (NCDC), National Oceanic and Atmospheric Administration (NOAA) for Global Historical Climate Network (GHCN) (Peterson et al. 1998).

\subsection{Analysis}

Different factors about population and temperature distribution should be considered prior to the study of HWs.

\subsubsection{Population distribution and sampling meteorological stations}

Mortality data are sorted by province, age and gender but not by municipality. On the other hand, long meteorological data series are mainly available close to the most populated cities, especially near or at the airports. A crucial point is to determine whether or not the provincial mortality data can be related with the particular temperature records at some specific locations and what percentage of the provincial population lives close to the area where the meteorological station is located or in adjacent areas with similar meteorological conditions. Galicia is a region with a high dispersion in population, where a significant percentage of the population lives in small towns of less than 30000 inhabitants. The following procedure was considered: (1) the population of every municipality according to the 2009 census, and that of each province, was obtained from the Instituto Español de Estadistica; (2) all municipalities located at $<25 \mathrm{~km}$ from the meteorological station were considered; (3) municipalities located between 25 and $50 \mathrm{~km}$ from the station were also considered except when separated by abrupt topographic changes; (4) the sum of population around the station, following the previous criteria was compared with the provincial population. Table 1 summarizes the percentage of population per province living under meteorological conditions similar to the ones measured by the sampling station. In all provinces, the percentage of population affected by the meteorological conditions measured by the reference station was higher than $70 \%$.

\subsubsection{Climatic areas}

According to recent research (Gómez-Gesteira et al. 2011, this issue), there is an important gradient

Table 1. Location and altitude of air temperature stations distributed along Galicia. Last column is the percentage of population living in every province close to the reference meteorological station. The criterion of proximity is described in the text

\begin{tabular}{|lcccc|}
\hline Station Name & Longitude & Latitude & Altitude $(\mathrm{m})$ & $\%$ \\
\hline Coruña & -8.42 & 43.37 & 58 & 70 \\
Lugo & -7.55 & 43.01 & 450 & 75 \\
Vigo & -8.63 & 42.22 & 255 & 76 \\
Ourense & -7.86 & 42.33 & 143 & 85 \\
\hline
\end{tabular}




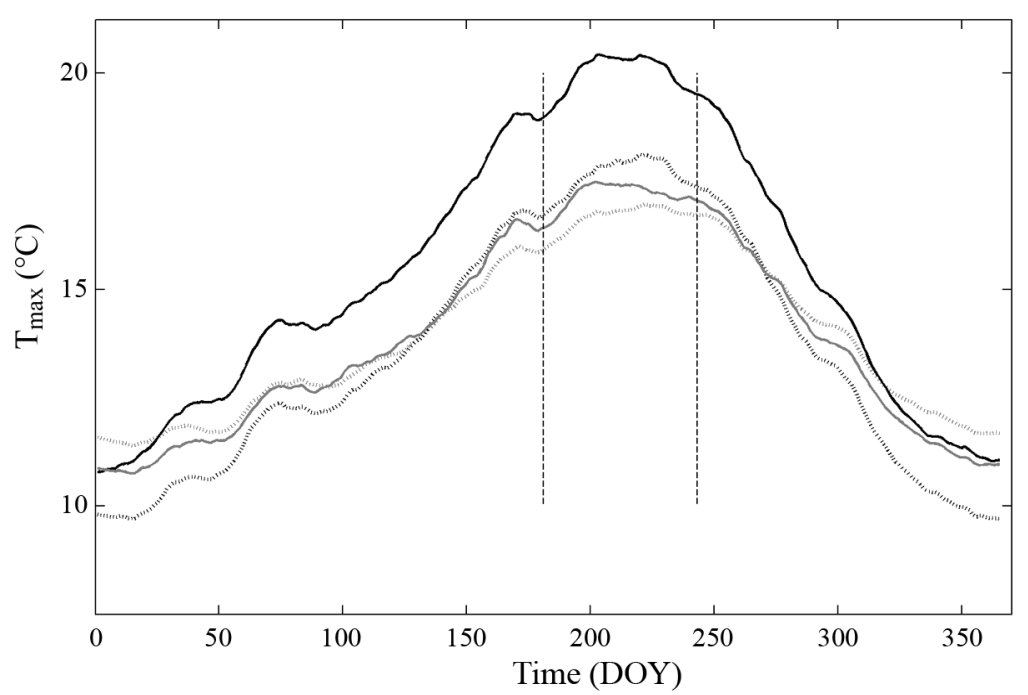

Fig. 1. Maximum temperatures at daily scale (day of the year, DOY). Values were averaged for the period 1973-2006. Grey dotted: Coruña; black dotted: Lugo; black solid: Ourense; and grey solid: Pontevedra. The vertical lines mark the interval July-August

between the Atlantic part of the region and the interior part enhanced by the presence of mountain ranges with a north-south orientation in the mid part of the region. In a first approximation the most populated areas of the provinces of Coruña and Pontevedra can be considered the maritime area and the provinces of Lugo and Ourense the interior region. This first classification can be considered too coarse due to the existence of important changes in latitude inside both macroareas. Actually, Gómez-Gesteira et al. (2011) consider a latitudinal gradient of $0.59^{\circ} \mathrm{C}$, which indicates that a second macroscopic classification can be considered between northern and southern provinces. Thus, 4 different climatic areas coinciding with the provinces can be considered for our purposes. Although the present classification can be affected by an error in terms of land surface, the error is negligible in terms of population.

The months with the highest maximum temperatures should be defined prior to analysis. The perpetual year was calculated at daily scale at the 4 provinces using data from 1987 to 2006 taken from the meterological station located in each region. Fig. 1 shows the maximum temperature $\left(\mathrm{T}_{\max }\right)$ corresponding to the perpetual year. The highest temperatures were observed in July and August. These will be the months considered in the present analysis of HWs.

\subsubsection{Method of defining HWs}

In general, 2 alternative methods can be considered as described in Montero et al. (2010). The first method uses a statistical-meteorological criterion. Basically, HW days are defined as the days that exceed a given percentile of the historical values. This method has been used in recent papers dealing with the 2003 HW in the Iberian Peninsula (Díaz et al. 2006, Trigo et al. 2009). The second method defines a trigger temperature which is computed in terms of the relationship between temperature and mortality. This method is used in different countries, e.g. Portugal (Nogueira \& Paixão 2008) or France (Pascal et al. 2006), to create the HW health warning system.

Both methods were compared by Montero et al. (2010) in the 5 provinces of Castilla-La Mancha as mentioned above. A similar analysis will be carried out here to decide whether or not a simple statistical-meteorological criterion can provide reliable results. Following Montero et al. (2010), the mortality time series for each province was modelled using Box-Jenkins stochastic procedures (Autoregressive Integrated Moving Average, ARIMA). In the present study, the mortality series covers the months of July and August over the period 1987-2006. For each province, the residuals series resulting from the modeling process of the mortallity time series were related to the maximum temperature time series grouped in $1^{\circ} \mathrm{C}$ intervals. Results show that the associated trigger temperatures cannot be univocally calculated from the scatterplot diagram, so intervals greater than the exact values are provided in Table 2. In general, values range from 93 to $96 \%$ in all of the Galician provinces. Averaging the intervals, the mean value is $94.5 \%$, which is close to the $95 \%$ value assumed in previous studies carried out in the Iberian Peninsula (Díaz et al. 2006, Trigo et al. 2009, García Herrera et al. 2010). In addition, no difference among provinces was observed in the previous analysis. In summary, a simple statistical-meteorological criterion assuming the $95 \%$ percentile will be considered in the further analysis.

It is a well known fact that the impact of extreme summer temperature on mortality increases drastically

Table 2. Percentile and associated trigger temperature ranges for the Galician provinces

\begin{tabular}{|lcc|}
\hline & $\begin{array}{c}\text { Percentile } \\
(\%)\end{array}$ & $\begin{array}{c}\text { Trigger temperature } \\
\left({ }^{\circ} \mathrm{C}\right)\end{array}$ \\
\hline Coruña & $93-96$ & $28.4-30.0$ \\
Lugo & $93-96$ & $33.0-34.0$ \\
Ourense & $93-96$ & $37.6-38.6$ \\
Pontevedra & $93-96$ & $31.8-32.8$ \\
\hline
\end{tabular}


when the 95th percentile of the local $\mathrm{T}_{\max }$ distribution $\left(T_{\max 95}\right)$ is exceeded (Díaz et al. 2006). Although there is not a universal definition to quantify HWs, in the present study a HW is a period of more than 3 consecutive hot days. A 'hot day' is defined as a $24 \mathrm{~h}$ period with a maximum temperature exceeding the long-term daily 95th percentile. The daily 95th percentiles, for each July-August day, were computed over the 1987 to 2006 period from samples of $30 \mathrm{yr} \times 15 \mathrm{~d}$ (the day in question and $7 \mathrm{~d}$ on either side of this day), improving the robustness of daily percentile estimations. These definitions are similar to the one considered in other studies (Della-Marta et al. 2007, Kuglitsch et al. 2010). The temperature exceedance associated to every HW will be computed following the previous studies (Díaz et al. 2006, Trigo et al. 2009) by means of

$\mathrm{T}_{\mathrm{exc}}=\left\{\begin{array}{cc}\sum_{i=1 \text { month }}^{i=31 \text { month }} \mathrm{T}_{\max , i}-\mathrm{T}_{\max 95, i} & \text { if } \mathrm{T}_{\max , i}>\mathrm{T}_{\max 95, i} \\ 0 & \text { otherwise }\end{array}\right.$

where month is July or August. $\mathrm{T}_{\mathrm{exc}}$ represents the sum of the daily Celsius degrees higher than the daily threshold percentile, $\mathrm{T}_{\max 95}$.

A similar criterion will be used to determine the mortality exceedance $\left(\mathrm{M}_{\text {exc }}\right)$, where the mortality per province has been normalized per 100000 inhabitants. As we mentioned above, only the population segment over $65 \mathrm{yr}$ will be considered in the present study and normalization in mortality will be relative to this population segment in every province.

$\mathrm{M}_{\mathrm{exc}}=\left\{\begin{array}{cl}\sum_{i=1 \text { month }}^{i=31 \text { month }} \mathrm{M}_{i}-\mathrm{M}_{95, i} & \text { if } \mathrm{M}_{i}>\mathrm{M}_{95, i} \\ 0 & \text { otherwise }\end{array}\right.$

Thus, the mortality exceedance will be analyzed on the dates for which potential HWs have been observed according to $\mathrm{T}_{\mathrm{exc}}$.

\section{RESULTS AND DISCUSSION}

The main HWs observed over the period 1987 to 2006 for the 4 Galician provinces are summarized in Table 3 . Only the HW observed in July 1990 was simultaneously detected at the 4 provinces although with different intensities. The maximum exceedance of temperature was observed in Lugo $\left(\mathrm{T}_{\mathrm{exc}}=16.0^{\circ} \mathrm{C}\right)$ and the minimum one in Pontevedra $\left(\mathrm{T}_{\mathrm{exc}}=6.0^{\circ} \mathrm{C}\right)$. In the interior provinces this HW showed a short secondary peak about one week later. The August 2003 HW was observed in all provinces except for Coruña that is missing data for this period. The maximum exceedance of temperature was measured in Pontevedra $\left(\mathrm{T}_{\mathrm{exc}}=17.5^{\circ} \mathrm{C}\right)$ and the minimum one was in Ourense $\left(\mathrm{T}_{\text {exc }}=9.4^{\circ} \mathrm{C}\right)$. In the particular case of Coruña, a real
Table 3. Heat waves observed over the period 1987-2006. The HWs marked with an asterisk correspond to the events observed in most of the provinces with a high impact on $\mathrm{T}_{\text {exc }}$ (sum of daily no. of degrees Celcius higher than the daily threshold percentile)

\begin{tabular}{|c|c|c|}
\hline Province & Date & $\mathrm{T}_{\text {exc }}\left({ }^{\circ} \mathrm{C}\right)$ \\
\hline \multirow[t]{3}{*}{ Coruña } & July $18-24,1990^{*}$ & 9.3 \\
\hline & August 18-20, 1993 & 15.7 \\
\hline & July 10-13, 2005 & 6.8 \\
\hline \multirow[t]{5}{*}{ Lugo } & August 12-15, 1987 & 12.0 \\
\hline & July 18-24, 1990* & 16.0 \\
\hline & August 1-4, 1990 & 10.0 \\
\hline & August $7-10,1998$ & 9.0 \\
\hline & August $3-12,2003^{*}$ & 16.6 \\
\hline \multirow[t]{4}{*}{ Ourense } & July $16-21,1990^{*}$ & 14.0 \\
\hline & August 1-4, 1990 & 4.6 \\
\hline & August 8-11, 1998 & 2.6 \\
\hline & August $3-12,2003^{*}$ & 9.4 \\
\hline \multirow[t]{4}{*}{ Pontevedra } & July 17-23, 1990* & 6.0 \\
\hline & August 22-28, 1995 & 5.3 \\
\hline & August 21-24, 1998 & 2.9 \\
\hline & August $6-12,2003^{*}$ & 17.5 \\
\hline
\end{tabular}

HW cannot be properly defined since $\mathrm{T}_{\max 95}$ was only exceeded on August 3 and August 12. Also note that the $\mathrm{T}_{\mathrm{exc}}$ averaged for the provinces where the HW was detected is higher in August 2003 than in July 1990. The rest of the HWs were only observed at a single province, except for the August 1998 HW that was simultaneously detected in Lugo, Ourense and Pontevedra, although with a low mean temperature exceedance $\left(\sim 3^{\circ} \mathrm{C}\right.$ in Ourense and Pontevedra, and $9^{\circ} \mathrm{C}$ in Lugo). Hereafter, the analysis will be focused on 2 main HWs (July 1990 and August 2003).

The atmospheric conditions observed during these HWs were characterized by composites of the $850 \mathrm{hPa}$ temperature and the $500 \mathrm{hPa}$ geopotential fields computed along the duration of the events. Fig. 2a corresponds with the hottest days of the 1990 summer (16 to 24 July, see Table 3), and shows the usual pattern of summer HWs for southwestern Europe characterized by strong ridges over the Iberian Peninsula and France and moving oceanward. During the July 1990 HW, the rest of Europe was not affected to the same extent as it was from the 2003 HW (Fig. 2b) (García-Herrera et al. 2005, Trigo et al. 2005, García-Herrera et al. 2010). The composites of temperature and geopotential fields measured from 3 to 14 August 2003 (see Table 3) are quite similar although with strong ridges over the Iberian Peninsula moving landward instead of oceanward (Fig. 2b). The temperature and geopotential anomalies emphasize the amplitude of both extreme events showing a similar air temperature anomaly patterns in both events but centered in the Bay of Biscay in 1990 (Fig. 2c) and around Nantes, France, in 2003 (Fig 2d). 

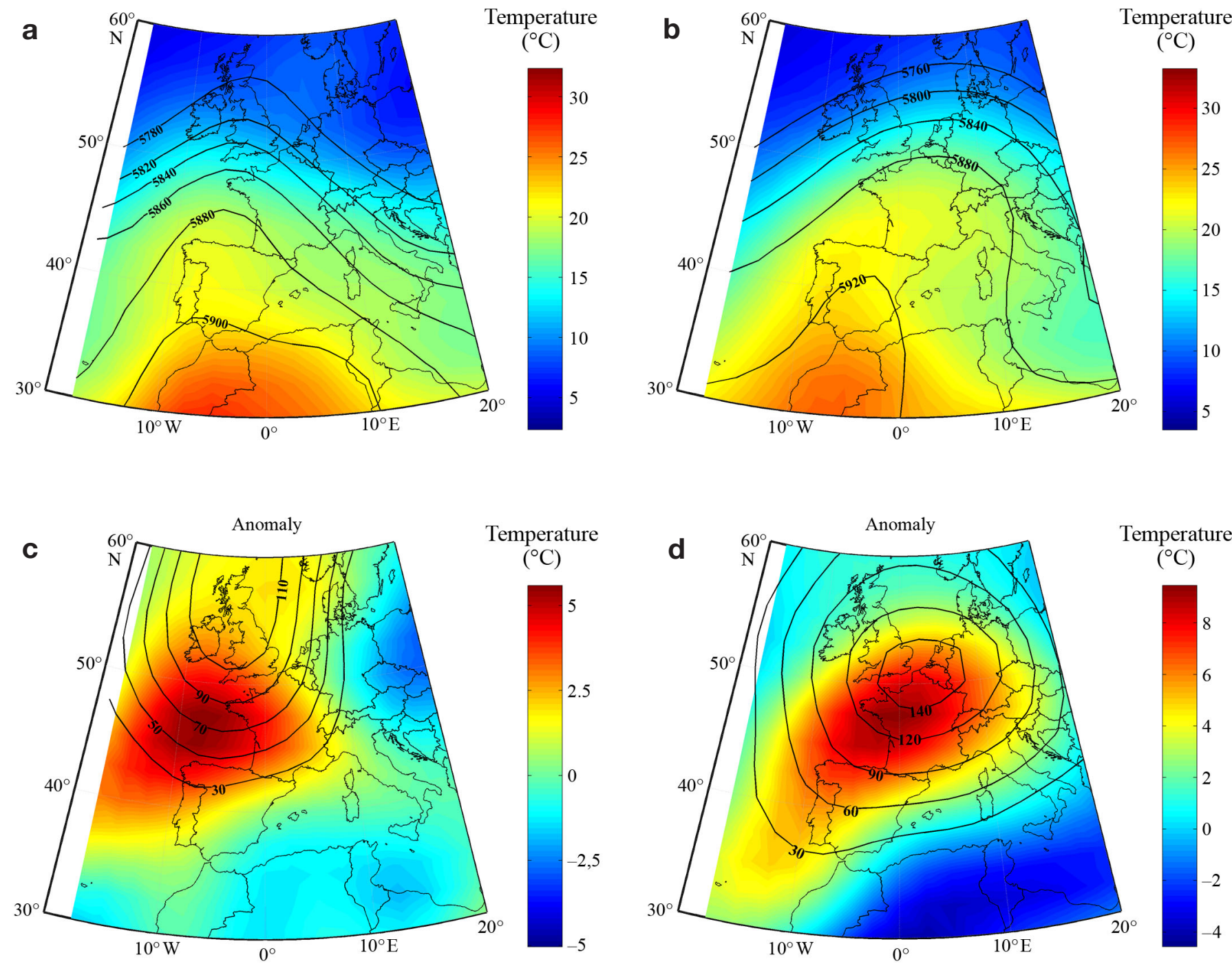

Temperature

$\left({ }^{\circ} \mathrm{C}\right)$

Fig. 2. Composite of air temperature (color maps ${ }^{\circ} \mathrm{C}$ ) at $850 \mathrm{hPa}$ height and $500 \mathrm{hPa}$ geopotential height (contour, geopotential meter, gpm) for the periods: (a) 16-24 July 1990 and (b) 3-14 August 2003. Composite of air temperature and geopotential height anomalies for the same periods in July (c) and in August (d). Anomalies were computed with respect to the daily average of the variable for the 1985-1995 period in (c) and for the 1998-2008 period in (d)

The anomaly was computed as the difference between the air temperature (geopotential height) for the period of interest (e.g. 16-24 July 1990) and the 5 yr running average temperature (geopotential height) for the period under study (e.g. 16-24 July from 1985 to 1995) in order to avoid long-term variations. The lowtropospheric air temperature anomaly field shows values around $4^{\circ} \mathrm{C}\left(7^{\circ} \mathrm{C}\right)$ in July 1990 (August 2003) in Galicia. The $500 \mathrm{hPa}$ geopotential height anomaly patterns show a positive anomaly maximum (>110 geopotential meters, gpm) centered on Great Britain in July 1990 (Fig. 2c) and a positive anomaly maximum (>140 gpm) centered in northern France in August 2003 (Fig. 2d).

Previous studies based on the 2003 HW define these synoptic patterns as blocking events (Ogi et al. 2005,
Trigo et al. 2005). Despite this, García-Herrera et al. (2010) concluded that the anomalous blocking during the first half of August 2003 was located eastward compared to previous studies on the climate impact of blocking episodes centered either over the Atlantic or Western Europe (e.g. Rex 1950, Trigo et al. 2004). Consequently, blocking was shown not to be the main reason for the $2003 \mathrm{HW}$. In contrast, in agreement with previous studies (e.g. Black et al. 2004), the northerly displacement of the Atlantic subtropical high was shown to be the more likely the mechanism responsible for the $2003 \mathrm{HW}$. In this context, the position of the Atlantic subtropical high computed from SLP data was analyzed over the period 1987 to 2006 (Fig. 3a,b). For each year, SLP fields were time averaged during the 2 HW periods (16-24 July and 3-14 August). Then, the 

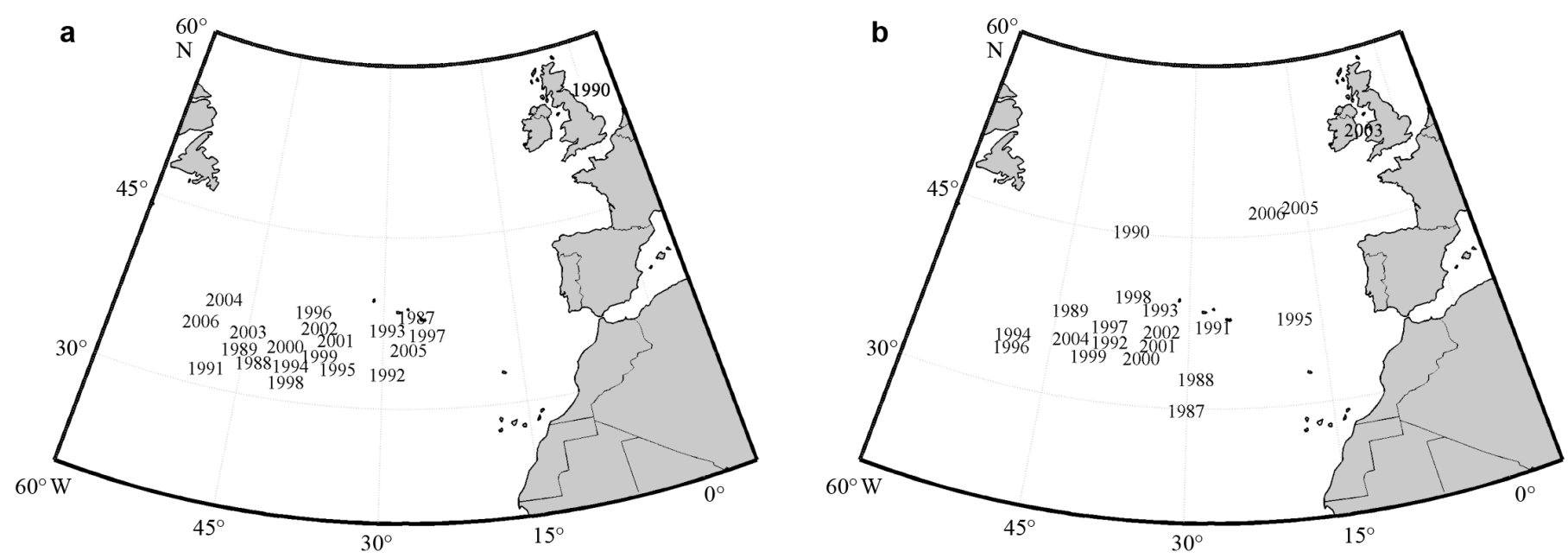

Fig. 3. Position of the Atlantic subtropical high over the 1987-2006 period: (a) 16-24 July, (b) 3-14 August

position of the maximum pressure was determined in the area ranging from $0-60^{\circ} \mathrm{W}$ and $25-60^{\circ} \mathrm{N}$. In both panels of Fig. 3, it is possible to observe the unusual position of the high in July 1990 (located east of Great Britain, see Fig. 3a) and the high in August 2003 (Fig. 3b) which is unusually displaced northeastwardly during both HWs. This confirms that there was an anomalous northerly displacement of the Atlantic subtropical high during the 2003 HW. Moreover, we found that for the July 1990 HW there was also a northeastward displacement of the Atlantic subtropical high being the probable cause for this HW.

The evaluation of the impact of HWs on human health is usually carried out by means of the analysis of the simultaneous evolution of both local (regional) maximum temperature and mortality rates. According to García-Herrera et al. (2005) significant mortality can occur up to $3 \mathrm{~d}$ after the end of the HWs. In this sense, $M_{\text {exc }}$ was computed over the duration of HWs and the following $3 \mathrm{~d}$. Note that the criterion used to calculate the HW impact on mortality is very restrictive because, during the $\mathrm{HW}$, the $\mathrm{M}_{\text {exc }}$ is computed only when mortality exceeds the long-term daily 95th percentile in a population over 65 yr. In addition, $M_{\text {exc }}$ was disaggregated per province and gender. The days with anomalous values in temperature (Table 3 ) were observed to give rise to anomalous values in mortality during both HWs (Table 4). In the case of Coruña in August 2003 the event cannot be properly considered a HW according to the criterion described above. In both HWs, the total $\mathrm{M}_{\text {exc }}$ was higher in the internal provinces than at the coastal ones. Comparing both HWs, the one in 1990 provoked a much higher increase in mortality (ranging from 3 to 5 times) than the one observed in 2003, even when the mean $\mathrm{T}_{\text {exc }}$ was slightly higher in 2003 as shown in Table 3. Possibly, the undeniable improvements in terms of welfare have provided a sociologi- cal adaptation to climate. According to the Instituto Nacional de Estadistica, the GDP of Galicia in 2003 was 2.4 times that of 1990. Thus, for example, the number of cars and homes with air conditioning has exponentially grown during the last decades. Some authors, Miron et al. (2008), have considered this socioeconomic development as one reason why a steeper rise in mortality was prevented despite the percentage increase in the elderly population. Possibly, physiological changes related to the general thermoregulation of the human body have also occurred during the last decades and the population is nowadays used to normal temperatures higher than in the past. Thus, although $\mathrm{T}_{\text {exc }}$ was similar during both HWs, the mean temperature around 1990 was considerably lower than around 2003. Thus, the increment-relative to the 'usual' temperature - was much higher in 1990 than in 2003. Unfortunately, it is extremely difficult to distinguish between the role played by sociological and physiological adaptations.

When $M_{\text {exc }}$ is disaggregated by gender, females were shown to be more susceptible than males to HWs. On average, $M_{\text {exc }}$ values were $\sim 1.5$ times higher for

Table 4. Excess mortality by gender ( $\mathrm{M}$ and $\mathrm{F}$ ) corresponding to the HWs detected in July 1990 and August 2003. $\mathrm{M}_{\mathrm{exc}}$ is calculated in deaths per $10^{5}$ inhabitants for the population segment $>65$ yr. Data were sorted by gender ( $M$ and W). Total values are marked with T. Figs. in parenthesis correspond to the actual deaths

\begin{tabular}{|lccccccc|}
\hline & \multicolumn{3}{c}{ July 1990 } & \multicolumn{4}{c|}{ August 2003 } \\
& M & F & T & M & F & T \\
\hline Coruña & $20(14)$ & $23(24)$ & $22(38)$ & - & - & - \\
Lugo & $20(6)$ & $28(12)$ & $25(18)$ & $2(1)$ & $6(3)$ & $4(4)$ \\
Ourense & $18(5)$ & $28(11)$ & $24(16)$ & $4(1)$ & $6(3)$ & $5(4)$ \\
Pontevedra & $9(5)$ & $26(21)$ & $19(26)$ & $3(2)$ & $10(10)$ & $7(12)$ \\
\hline
\end{tabular}


females, similar to values given by García-Herrera et al. (2005) and Trigo et al. (2009). According to Shapiro et al. (1980), thermoregulation differences between females and males are minimal and climate specific, with females performing better (worse) in warm/ humid (hot/dry) climates. Possibly, the main differences in mortality are due to social differences between both genders.

\section{CONCLUSIONS}

We identified 2 major HWs that occurred in Galicia over the 1987-2006 period - the first in July 1990 and the second in August 2003-by studying those days when the temperature exceeded the 95th percentile of the maximum temperature for 4 provinces of Galicia. Additionally, the impact on excessive mortality for both heat waves was also analyzed.

The 3 most important results are: (1) The temperature exceedance in Galicia was similar during both HWs but only the second one had been reported so far in Galicia, possibly due to the fact that the HW in August 2003 affected several European countries and the one in July 1990 was a more localized event. (2) The 1990 HW had a higher effect on the mortality of the population segment over $65 \mathrm{yr}$ that can be attributed to sociological and physiological adaptation, and thermoregulation differences that affected the female population more than the male population in both HWs. (3) We also studied the position of the Atlantic subtropical high over the 2 HWs. Both had similar synoptic situations, characterized by a northeastward displacement of the Atlantic subtropical high but the temperature anomaly in 1990 was centered in the Bay of Biscay and the one in 2003 was located more extended over the European continent.

In summary, the lack of comprehensive studies about HWs in Galicia was the main motivation for this study. We provide new insights about the mortality caused by the $2003 \mathrm{HW}$, and the previously unstudied $1990 \mathrm{HW}$ in Galicia that until recently had gone unrecognized as a major HW.

Acknowledgements. This work is supported by the Xunta de Galicia under the project 10PXIB 383169PR.

\section{LITERATURE CITED}

Black E, Blackburn M, Harrison G, Hoskins B, Methven J (2004) Factors contributing to the summer 2003 European heat wave. Weather 59:217-223

> Davis RE, Knappenberger PC, Michaels PJ, Novicoff WM and others (2003) Changing heat-related mortality in the United States. Environ Health Perspect 111:1712-1718

Della-Marta PM, Haylock MR, Luterbacher J, Wanner H,
(2007) Double length of western Europen summer heat waves since 1880. J Geophys Res 112:D15103. doi:10.1029/ 2007JD008510

> Dessai S (2002) Heat stress and mortality in Lisbon. Part I: model construction and validation. Int $\mathrm{J}$ Biometeorol 47: 6-12

Díaz J, Linares C, García-Herrera R, López C, Trigo R (2004) Impact of temperature and air pollution on the mortality of children in Madrid. J Occup Environ Med 46:768-774

Díaz J, Garcia-Herrera R, Trigo RM, Linares C, Valente MA, De Miguel JM, Hernandez E (2006) The impact of summer 2003 heat wave in Iberia: how should we measure it? Int J Biometeorol 50:159-166

> Diffenbaugh NS, Pal JS, Giorgi F, Xuejie G (2007) Heat stress intensification in the Mediterranean climate change hotspot. Geophys Res Lett 34:L11706. doi:10.1029/2007GL030000

García-Herrera R, Díaz J, Trigo RM, Hernandez E (2005) Extreme summer temperatures in Iberia: health impacts and associated synoptic conditions. Ann Geophys 23: $239-251$

García-Herrera R, Díaz J, Trigo RM, Luterbacher J, Fischer EM (2010) A review of the European summer heat wave of 2003. Crit Rev Environ Sci Tech.40:267-306

Gershunov A, Cayan DR, Iacobellis SF (2009) The great 2006 heat wave over California and Nevada: signal of an increasing trend. J Clim 22:6181-6203

- Gómez-Gesteira M, Gimeno L, deCastro M, Lorenzo MN and others (2011) The state of climate in North-West Iberia. Clim Res 48:109-144

Havenith G (2001) Individualized model of human thermoregulation for the simulation of heat stress response. J Appl Physiol 90:1943-1954

INS (Instituto Nacional de Saude Dr. Ricardo Jorge) (2008) The impact of air conditioning in hospital mortality during the 2003 heatwave. Instituto Nacional de Saude Dr. Ricardo Jorge, Lisbon

InVS (Institute de Veille Sanitaire) (2003) Impact sanitaire de la vague de chaleur en France survenue en août 2003. Rapport d'etape-29 aout 2003 (Progress report on the heat wave 2003 in France). Institut De Veille SanitaireInVS (National Institute of Public Health Surveillance), Saint Maurice

IPCC (Intergovernmental Panel on Climate Change) (2007) Climate change 2007: the physical science basis. In: Solomon S, Qin D, Manning M, Chen Z and others (eds) Contribution of Working Group I to the Fourth Assessment Report of the Intergovernmental Panel on Climate Change. Cambridge University Press, Cambridge

Kalkstein LS (1993) Health and climate change-direct impacts in cities. Lancet 342:1397-1399

Kalnay E, Kanamitsu M, Kistler R, Collins W and others (1996) The NCEP/NCAR 40-year reanalysis project. Bull Am Meteorol Soc 77:437-470

> Kuglitsch FG, Toreti A, Xoplaki E, Della-Marta PM, Zeferos CS, Turkes M, Luterbacher J (2010) Heat wave changes in the eastern Mediterranean since 1960. Geophys Res Lett 37:L04802. doi:10.1029/2009GL041841

Lage Ferrón MB, Díaz Jímenez J, Gestal Otero JJ, de la Sierra Pajares Ortíz M, Alberdi Odriozola JC (1999) The influence of environmental factors on the number of emergency room admissions at the Juan Canalejo medical center complex in Coruña: creation of a prediction model. Rev Esp Salud Publica 73:45-60

> Luterbacher J, Dietrich D, Xoplaki E, Grosjean M, Wanner H (2004) European seasonal and annual temperature variability, trends and extremes since 1500. Science 303: 1499-1503 
Miron JI, Criado-Alvarez JJ, Diaz J, Linares C. Mayoral S, Montero JC (2008) Time trends in minimum mortality temperatures in Castile-La Mancha (central Spain): 19752003. Int J Biometeorol 52:291-9

Montero JC, Miron IJ, Criado JJ, Linares C, Diaz J (2010) Comparison between 2 methods of defining heat waves: a retrospective study in Castile-La Mancha (Spain). Sci Total Environ 408:1544-1550

Munich Re (2004) TOPICS geo: annual review natural castrophes 2003. Münchener Rückversicherungs-Gesellschaft, Munich

Nogueira PJ, Paixão E (2008) Models for mortality associated with heatwaves: update of the Portuguese heat health warning system. Int J Climatol 28:545-562

Ogi M, Yamazaki K, Tachibana Z (2005) The summer northern annular mode and abnormal summer weather in 2003. Geophys Res Lett 32:L04706 doi: 10.1029/2004GL 021528

Pan WH, Li LA, Tsai MJ (1995) Temperature extremes and mortality from coronary heart disease and cerebral infarction in elderly Chinese. Lancet 345:353-355

Pascal M, Laaidi K, Ledrans M, Baffert E and others (2006) France's heat health watch warning system. Int J Biometerol 50:144-153.

Peterson TC, Vose R, Schmoyer R, Razuvaev V (1998) Global historical climatology network (GHCN) quality control of

Submitted: May 5, 2010; Accepted: January 3, 2011 monthly temperature data. Int J Climatol 18:1169-1179

Rex DF (1950) Blocking action in the middle troposphere and its effect upon regional climate. I. An aerological study of blocking action. Tellus 2:196-211

Robinson PJ (2001) On the definition of a heat wave. J Appl Meteorol 40:762-775

Schär C, Vidale PL, Luthi D, Frei C, Haberli C, Liniger MA, Appenzeller C (2004) The role of increasing temperature variability in European summer heat waves. Nature 427: 332-336

> Shapiro Y, Pandolf KB, Avellini BA, Pimental NA, Goldman RF (1980) Physiological responses of men and women to humid and dry heat. J Appl Physiol 49:1-8

Trigo RM, Trigo IM, DaCamara CC, Osborn TJ (2004) Winter blocking episodes in the European-Atlantic sector: climate impacts and associated mechanism in the reanalysis. Clim Dyn 23:17-28

> Trigo RM, García-Herrera R, Díaz J, Franco Trigo I, Valente MA (2005) How exceptional was the early August 2003 heatwave in France? Geophys Res Lett 32:L10701 doi: 10.1029/2005GL022410

Trigo RM, Ramos AM, Nogueira PJ, Santos FD, Garcia-Herrera R, Gouveia C, Santo FE (2009) Evaluating the impact of extreme temperature based indices in the 2003 heatwave excessive mortality in Portugal. Environ Sci Policy $12: 844-854$

Proofs received from author(s): August 4, 2011 